CLINICAL STUDY

\title{
Prostate volume and growth during testosterone replacement therapy is related to visceral obesity in Klinefelter syndrome
}

\author{
R Selice, N Caretta, A Di Mambro, M Torino, P Palego, A Ferlin and C Foresta \\ Department of Molecular Medicine, Section of Clinical Pathology and Center for Human Reproduction Pathology, University of Padova, Via Gabelli 63, \\ 35121 Padova, Italy \\ (Correspondence should be addressed to C Foresta; Email: carlo.foresta@unipd.it)
}

\begin{abstract}
Objective: Klinefelter syndrome (KS) is a chromosomal alteration characterized by increased risk of metabolic syndrome, mainly caused by visceral obesity. In the last years, obesity has been studied as a potential risk factor for prostate disease and recently a link has been demonstrated between visceral adiposity with prostate volume. The aim of this study was to analyze the relationship between obesity and prostate volume and growth during testosterone therapy in KS subjects.

Design and methods: We evaluated reproductive hormones, metabolic parameters, anthropometric measures, PSA, and prostate volume in 121 naïve non-mosaic KS patients and 60 age-matched healthy male controls. Fifty-six KS hypogonadic subjects were treated with testosterone-gel $2 \%$ and reevaluated after 18 months of treatment.

Results: Prostate volume in KS was positively related to waist circumference (WC). The KS group with WC $\geq 94 \mathrm{~cm}$ had significantly higher prostate volume, BMI, insulin plasma levels, homeostasis model assessment index, total cholesterol, triglycerides, and glycemia with respect to the KS group with WC $<94 \mathrm{~cm}$. After testosterone replacement therapy, only hypogonadic KS men with WC $\geq 94 \mathrm{~cm}$ had a statistically significant increase in prostate volume. Furthermore, in untreated KS subjects, prostate volume showed a statistically significant increase after 18 months of follow-up only in subjects with WC $\geq 94 \mathrm{~cm}$.

Conclusions: This study showed that visceral obesity, insulin resistance, and lipid and glucose metabolism alterations are associated with prostate volume and growth during testosterone replacement therapy in KS, independently from androgen or estrogen levels. These latter findings might provide the basis for a better management and follow-up of KS subjects.
\end{abstract}

European Journal of Endocrinology 169 743-749

\section{Introduction}

Klinefelter syndrome (KS) is the most common sex chromosomal disorder, with a prevalence of 1:600 males and it is a frequent form of male hypogonadism and infertility (1). KS is characterized by the presence of one or more extra X chromosomes; about $80 \%$ of cases have $47, \mathrm{XXY}$ karyotype, the remaining 20\% have higher grade chromosome aneuploidies (48,XXXY; 48,XXYY; and 49,XXXXY), mosaicisms (46,XY/47,XXY), or structurally abnormal X chromosomes (1). The chromosome aberration arises by maternal or paternal non-disjunction during meiotic division in germ cell development or rarely in early embryonic mitotic cell divisions (1).

The clinical features of KS commonly include hypergonadotropic hypogonadism, gynecomastia, small testes, and azoospermia (2), but this syndrome might also be associated with an increased risk of systemic diseases including malignancies, osteoporosis (3), venous thromboembolism (4), diabetes, obesity, insulin resistance, metabolic syndrome, and cardiovascular diseases $(5,6,7,8)$.

In the last years, obesity has been studied as a potential risk factor for prostate disease. Various studies consistently showed that increased adiposity is positively associated with prostate enlargement and increased risk of benign prostatic hyperplasia (BPH) (9). Of almost 26000 male participants in the Health Professionals Follow-up Study, those with an obese waist circumference $(\mathrm{WC})(>109 \mathrm{~cm})$ were $38 \%$ more likely to undergo BPH surgery than those with a nonobese WC $(<89 \mathrm{~cm})(10)$, and data from the Prostate Cancer Prevention Trial (PCPT) indicated a $10 \%$ increased risk for total and severe $\mathrm{BPH}$ for every $5 \mathrm{~cm}$ increase in waist:hip ratio (11). Furthermore, a link has been demonstrated between insulin resistance and visceral adiposity with prostate volume markers among apparently healthy men and several reports have demonstrated a strong association between high insulin and leptin levels with BPH $(12,13)$. 
No study examined the relationship between obesity and prostate volume and growth during testosterone replacement therapy in KS. This is particularly intriguing because KS patients are often affected by hypergonadotropic hypogonadism requiring lifelong substitution therapy. Although no study has documented any direct evidence that testosterone therapy increases incident prostate cancer risk $(14,15)$, it is still difficult to argue that androgen replacement is completely safe and careful monitoring for prostate diseases is considered good practice during testosterone replacement therapy (16). The role of testosterone therapy in prostate growth in KS has been evaluated in a relatively small cohort group (17), and its association with metabolic parameters and obesity has never been examined.

\section{Subjects and methods}

\section{Patients and clinical analysis}

We studied, in a prospective study, 121 non-mosaic KS patients (mean age $31.5 \pm 8.7$ years; range 15-44 years), diagnosed at the Centre for Human Reproduction Pathology at the University of Padova from January 2007 to July 2010 after referral for fertility problems or testicular hypotrophy and 60 age-matched healthy (good general condition) and fertile (who recently fathered) male controls (mean age 30.9 \pm 8.4 years; range $19-45$ years), recruited through an andrological screening program. All subjects (patients and controls) underwent peripheral karyotype analysis, evaluating at least 50 peripheral blood lymphocyte metaphases, and had never received testosterone substitution at the time of evaluation.

Patients with more than one supernumerary $\mathrm{X}$ chromosome, mosaicisms, or with any endocrine dysfunction different from hypogonadism and subjects assuming any drug were excluded from the study. The study has been approved by the Hospital Ethics Committee and each participant gave his written informed consent.

Subject evaluation included complete medical history (pubertal history, lifestyle, physical activity, smoking, and alcohol misuse), physical examination (weight, height, BMI, WC, arm span, and blood pressure), reproductive hormone (LH, FSH, total testosterone, estradiol $\left(\mathrm{E}_{2}\right)$ ) levels, lipid and glucose metabolism (total cholesterol, HDL, triglycerides, and fasting glucose), hemochrome, serum insulin, and PSA. Homeostasis model assessment for insulin resistance (HOMA-IR) was calculated as fasting insulin $(\mu \mathrm{IU} / \mathrm{ml}) \times$ fasting glucose $(\mathrm{mmol} / \mathrm{l}) / 22.5$. According to the 2005 International Diabetes Federation (IDF) definition, central obesity was defined as WC $\geq 94 \mathrm{~cm}$ (18). Blood pressure was measured under fasting conditions, between 0800 and $1000 \mathrm{~h}$, avoiding cigarette smoking for a minimum of $12 \mathrm{~h}$.

The AR function and sensitivity was studied through the evaluation of the CAG repeat length and inactivating status. The AR gene is located on the $\mathrm{X}$ chromosome, and therefore in KS, it is present in double copy. The inactivation rate of the two $\mathrm{X}$ chromosomes, and the effective CAG repeat value in heterozygous KS men, was calculated as an X-weighted biallelic mean (19). This analysis was based on methylation-specific PCR at the human AR locus, with primers spanning the $(\mathrm{CAG}) n$ polymorphism region, as described previously (20).

Of 121 patients, 63 had hypogonadism (total testosterone $<10.4 \mathrm{nmol} / \mathrm{l}) \quad(21)$ and were treated with T-gel 2\% (Tostrex, ProStrakan, Galashiels, UK), dose adapted to maintain plasma testosterone levels between 12 and $18 \mathrm{nmol} / \mathrm{l}$. Fifty-six patients completed the treatment protocol and were reevaluated after 18 months by means of total testosterone, $\mathrm{E}_{2}$, LH, FSH, and PSA levels; metabolic parameters; hemochrome; and prostate volume by ultrasound (see below). Untreated KS subjects were reevaluated for prostate volume after 18 months of follow-up. These subjects were untreated because the testosterone level was $>10.4 \mathrm{nmol} / \mathrm{l}$.

\section{Hormone assays}

Blood was collected in the fasting state between 0800 and $1000 \mathrm{~h}$. Serum FSH, LH, total testosterone, and $\mathrm{E}_{2}$ were evaluated by commercial electrochemiluminescence immunoassay methods (Elecsys 2010, Roche Diagnostics). For all parameters, the intra- and interassay coefficients of variation $(\mathrm{CV})$ were $<8$ and $10 \%$ respectively.

\section{Prostate ultrasound}

Prostate transrectal analysis was performed by the same experienced operator ( $\mathrm{N}$ Caretta), blinded to patient clinical status, with a high-resolution Echo-ColorDoppler (iU22 Philips, Eindhoven, The Netherlands) equipped with a 9-5 $\mathrm{MHz}$ Broadband Curved Array Transducer. Prostate volume was calculated using the standard ellipsoid formula (width $\times$ height $\times$ length $\times$ $\pi / 6, \mathrm{CV})(22)$. Intra-observer variability was estimated to be $<10 \%$.

\section{Statistical analysis}

Relationships between continuous variables were assessed using the test for linear correlation. Differences in variables between KS patients and controls and KS patients on the basis of WC $\geq 94$ or $<94 \mathrm{~cm}$ were evaluated by unpaired two-sided Student's $t$-test after acceptance of normality and Bonferroni's correction for multiple comparisons. Differences in prevalence 
Table 1 Baseline clinical, metabolic, and hormonal parameters and anthropometric measures in 121 Klinefelter patients compared with 60 controls.

\begin{tabular}{|c|c|c|c|}
\hline Variable & $\begin{array}{c}\text { KS } \\
(n=121)\end{array}$ & $\begin{array}{c}\text { Controls } \\
(n=60)\end{array}$ & $\boldsymbol{P}$ \\
\hline Age (years) & $31.5 \pm 8.7$ & $30.9 \pm 8.4$ & NS \\
\hline Height $(\mathrm{cm})$ & $181.4 \pm 8.0$ & $179.8 \pm 6.2$ & NS \\
\hline Weight (kg) & $83.8 \pm 16.9$ & $77.5 \pm 12.4$ & $<0.05$ \\
\hline BMI $\left(\mathrm{kg} / \mathrm{m}^{2}\right)$ & $25.5 \pm 4.8$ & $23.6 \pm 3.7$ & $<0.05$ \\
\hline Waist $(\mathrm{cm})$ & $97.6 \pm 15.4$ & $85.8 \pm 10.2$ & $<0.0001$ \\
\hline $\operatorname{Arm}$ span $(\mathrm{cm})$ & $181.6 \pm 14.3$ & $178.9 \pm 7.1$ & NS \\
\hline Total testosterone (nmol/l) (r.v., 10-29) & $11.2 \pm 4.7$ & $17.4 \pm 3.8$ & $<0.0001$ \\
\hline LH (IU/I) (r.v., 1-9) & $20.1 \pm 6.4$ & $4.1 \pm 2.2$ & $<0.0001$ \\
\hline FSH (IU/I) (r.v., 1-8) & $37.3 \pm 32.7$ & $3.8 \pm 1.8$ & $<0.0001$ \\
\hline Estradiol (pmol/l) (r.v., 25-130) & $110.9 \pm 34.4$ & $95.2 \pm 33.0$ & $<0.0005$ \\
\hline $\mathrm{LH} /$ testosterone & $2.36 \pm 2.10$ & $0.3 \pm 0.15$ & $<0.0001$ \\
\hline Testosterone/ $\mathrm{E}_{2}$ & $0.10 \pm 0.05$ & $0.2 \pm 0.1$ & $<0.0001$ \\
\hline Weighted CAG repeats $(n)$ & $22.0 \pm 3.1$ & $21.4 \pm 2.1$ & NS \\
\hline Glycemia (mg/dl) (r.v., 50-110) & $80.6 \pm 13.7$ & $77.8 \pm 7.4$ & NS \\
\hline Insulin (mU/l) (r.v., <29.1) & $9.6 \pm 7.6$ & $4.3 \pm 6.4$ & $<0.0001$ \\
\hline HOMA-IR & $1.94 \pm 1.64$ & $0.79 \pm 0.56$ & $<0.0001$ \\
\hline Total cholesterol (mg/dl) (r.v., 120-200) & $191.6 \pm 43.4$ & $181.4 \pm 42.4$ & NS \\
\hline HDL (mg/dl) (r.v., > $>40)$ & $49.3 \pm 12.3$ & $52.2 \pm 8.0$ & NS \\
\hline Triglycerides (mg/dl) (r.v., <150) & $117.6 \pm 169.9$ & $102.6 \pm 43.8$ & NS \\
\hline Systolic blood pressure $(\mathrm{mmHg})($ r.v., $<130)$ & $124.0 \pm 11.8$ & $120.8 \pm 9.2$ & NS \\
\hline Diastolic blood pressure $(\mathrm{mmHg})($ r.v., $<85)$ & $76.5 \pm 7.4$ & $74.9 \pm 7.8$ & NS \\
\hline Prostate volume (ml) (r.v., 10-29) & $17.0 \pm 6.8$ & $21.0 \pm 5.4$ & $<0.0001$ \\
\hline PSA $(\mu \mathrm{g} / \mathrm{l})($ r.v., $<4)$ & $0.69 \pm 1.01$ & $0.74 \pm 1.04$ & NS \\
\hline
\end{tabular}

r.v., reference value; NS, not statistically significant.

between groups were analyzed by $\chi^{2}$ test. Differences in variables between baseline and after testosterone therapy in patients affected by hypogonadism were evaluated by paired two-sided Student's $t$-test. The significance level was set to $P<0.05$. Variables are given as mean \pm s.D. of the mean.

\section{Results}

Table 1 reports clinical, metabolic, and hormonal parameters, and anthropometric measures in KS patients and controls. KS patients had significantly higher weight, WC, BMI, gonadotropins, $\mathrm{E}_{2}$, insulin, and HOMA-IR and significantly reduced total testosterone levels and prostate volume with respect to controls.

After adjusting for age and testosterone plasma levels, prostate volume was positively associated with $\mathrm{WC}$ in KS group (adj. $r=0.20 ; P<0.05$ ). On the contrary, no correlation was found between prostate volume and testosterone and $\mathrm{E}_{2}$ plasma levels, $\mathrm{E}_{2}$ :testosterone or LH:testosterone ratio, and weighted CAG repeats and metabolic parameters (data not shown) except for total cholesterol $(R=0.21 ; P<0.05)$.

Furthermore, analysis of subgroups of KS patients with reduced testosterone plasma levels $(<10.4 \mathrm{nmol} / \mathrm{l})$ with respect to the subgroup with normal testosterone plasma levels $(\geq 10.4 \mathrm{nmol} / \mathrm{l})$ showed no significant difference in prostate volume $(17.9 \pm 8.4$ vs $16.0 \pm$ $5.0 \mathrm{ml}$ respectively). Seventy-two $(59.5 \%) \mathrm{KS}$ patients had WC $\geq 94 \mathrm{~cm}$ and $49(41.5 \%)$ had WC $<94 \mathrm{~cm}$.
Table 2 shows clinical, metabolic, and hormonal parameters and anthropometric measures in these two groups. Subjects with WC $\geq 94 \mathrm{~cm}$ had higher prostate volume with respect to those with WC $<94 \mathrm{~cm}$ $(18.3 \pm 8.0$ vs $14.9 \pm 4.3 \mathrm{ml})$. Furthermore, subjects

Table 2 Baseline clinical, metabolic, and hormonal parameters and anthropometric measures in KS patients on the basis of waist circumference $(\mathrm{WC}) \geq 94$ or $<94 \mathrm{~cm}$.

\begin{tabular}{|c|c|c|c|}
\hline & $\begin{array}{c}\text { WC }<94 \mathbf{c m} \\
(n=49)\end{array}$ & $\begin{array}{c}\mathbf{W C} \geq \mathbf{9 4} \mathbf{c m} \\
(n=72)\end{array}$ & $P$ \\
\hline Age (years) & $28.6 \pm 8.0$ & $30.7 \pm 9.2$ & NS \\
\hline Height (cm) & $180.4 \pm 7.4$ & $181.7 \pm 8.3$ & NS \\
\hline Weight (kg) & $70.4 \pm 7.9$ & $93.2 \pm 15.1$ & $<0.00001$ \\
\hline $\mathrm{BMI}\left(\mathrm{kg} / \mathrm{m}^{2}\right)$ & $21.5 \pm 2.2$ & $28.2 \pm 4.2$ & $<0.00001$ \\
\hline Waist $(\mathrm{cm})$ & $83.0 \pm 6.6$ & $107.4 \pm 11.2$ & $<0.00001$ \\
\hline Arm span $(\mathrm{cm})$ & $180.7 \pm 8.4$ & $182.2 \pm 17.3$ & NS \\
\hline $\begin{array}{l}\text { Total testosterone } \\
(\mathrm{nmol} / \mathrm{l})\end{array}$ & $14.0 \pm 4.6$ & $9.2 \pm 3.8$ & $<0.00001$ \\
\hline LH (IU/I) & $21.3 \pm 6.2$ & $19.5 \pm 6.4$ & NS \\
\hline FSH (IU/I) & $44.6 \pm 48.7$ & $32.3 \pm 12.1$ & NS \\
\hline Estradiol (pmol/l) & $119.3 \pm 35.6$ & $105.1 \pm 32.6$ & $<0.05$ \\
\hline LH/testosterone & $1.7 \pm 0.9$ & $2.8 \pm 2.5$ & $<0.005$ \\
\hline Testosterone/ $E_{2}$ & $0.12 \pm 0.04$ & $0.09 \pm 0.03$ & $<0.00001$ \\
\hline $\begin{array}{l}\text { Weighted CAG } \\
\text { repeats }(n)\end{array}$ & $21.9 \pm 2.7$ & $22.1 \pm 3.4$ & NS \\
\hline Glycemia (mg/dl) & $74.1 \pm 9.6$ & $85.1 \pm 14.4$ & $<0.00001$ \\
\hline Insulin (mU/l) & $5.8 \pm 3.6$ & $12.1 \pm 8.5$ & $<0.00001$ \\
\hline HOMA-IR & $1.05 \pm 0.9$ & $2.5 \pm 1.8$ & $<0.00001$ \\
\hline Total cholesterol (mg/dl) & $180.8 \pm 32.2$ & $199.0 \pm 48.5$ & $<0.05$ \\
\hline $\mathrm{HDL}(\mathrm{mg} / \mathrm{dl})$ & $52.0 \pm 11.6$ & $47.7 \pm 11.5$ & NS \\
\hline Triglycerides (mg/dl) & $77.4 \pm 39.1$ & $143.3 \pm 212.0$ & $<0.05$ \\
\hline Prostate volume $(\mathrm{ml})$ & $14.9 \pm 4.3$ & $18.3 \pm 8.0$ & $<0.05$ \\
\hline PSA $(\mu \mathrm{g} / \mathrm{l})$ & $0.54 \pm 0.35$ & $0.79 \pm 1.3$ & NS \\
\hline
\end{tabular}

NS, not statistically significant. 
Table 3 Hormonal, clinical, and biochemical parameters of hypogonadic patients with waist circumference (WC) $\geq 94$ and $<94 \mathrm{~cm}$ at baseline and after an 18-month period of therapy with testosterone.

\begin{tabular}{|c|c|c|c|c|}
\hline & \multicolumn{2}{|c|}{ Hypogonadic WC $<94 \mathrm{~cm}(n=18)$} & \multicolumn{2}{|c|}{ Hypogonadic WC $\geq 94 \mathrm{~cm}(n=38)$} \\
\hline & Baseline & After treatment & Baseline & After treatment \\
\hline LH (IU/I) & $22.5 \pm 5.2$ & $11.7 \pm 3.3^{\dagger}$ & $20.6 \pm 6.2$ & $10.1 \pm 4.3^{\dagger}$ \\
\hline FSH (IÚ/I) & $26.3 \pm 6.4$ & $13.2 \pm 5.4^{\dagger}$ & $28.1 \pm 6.3$ & $15.2 \pm 4.9^{\dagger}$ \\
\hline Total testosterone $(\mathrm{nmol} / \mathrm{l})$ & $8.1 \pm 2.3$ & $14.8 \pm 3.7^{\dagger}$ & $7.4 \pm 3.2$ & $15.1 \pm 4.5^{\dagger}$ \\
\hline Estradiol (pmol/l) & $88.1 \pm 35.8$ & $114.9 \pm 41.4^{*}$ & $91.4 \pm 41.0^{*}$ & $110.6 \pm 37.3^{*}$ \\
\hline Hematocrit (\%) & $42.4 \pm 1.8$ & $46.1 \pm 2.8^{\dagger}$ & $43.3 \pm 1.5$ & $47.2 \pm 2.2^{\dagger}$ \\
\hline Hemoglobin $(g / l)$ & $14.6 \pm 0.7$ & $15.2 \pm 0.9^{\ddagger}$ & $14.2 \pm 0.8$ & $14.9 \pm 0.9^{\ddagger}$ \\
\hline PSA $(\mu \mathrm{g} / \mathrm{l})$ & $0.44 \pm 0.22$ & $0.59 \pm 0.27$ & $0.55 \pm 0.21$ & $0.79 \pm 0.22^{\dagger}$ \\
\hline Prostate volume $(\mathrm{ml})$ & $14.4 \pm 3.3$ & $15.7 \pm 3.4$ & $18.2 \pm 7.3$ & $26.9 \pm 8.1^{\dagger}$ \\
\hline Weight $(\mathrm{kg})$ & $70.0 \pm 7.8$ & $70.2 \pm 7.4$ & $88.1 \pm 10.4$ & $87.8 \pm 9.8$ \\
\hline $\operatorname{BMI}\left(\mathrm{kg} / \mathrm{m}^{2}\right)$ & $21.5 \pm 2.1$ & $21.3 \pm 2.2$ & $26.4 \pm 2.4$ & $26.1 \pm 2.6$ \\
\hline Waist (cm) & $83.2 \pm 6.4$ & $83.0 \pm 5.8$ & $103.4 \pm 6.6$ & $103.8 \pm 6.4$ \\
\hline
\end{tabular}

${ }^{\star} P<0.05$ vs baseline ${ }^{\dagger} P<0.0001$ vs baseline, and ${ }^{\ddagger} P<0.05$ vs baseline.

with WC $\geq 94 \mathrm{~cm}$ had higher BMI, insulin plasma levels, HOMA index, total cholesterol, triglycerides, and glycemia with respect to those with $\mathrm{WC}<94 \mathrm{~cm}$. As expected, the group with $\mathrm{WC} \geq 94 \mathrm{~cm}$ had lower testosterone plasma levels and testosterone: $\mathrm{E}_{2}$ ratio with respect to that with $W C<94 \mathrm{~cm}$. No difference was noted in mean weighted CAG length and PSA levels between the two groups. As expected, the prevalence of hypogonadic subjects (testosterone $<10.4 \mathrm{nmol} / \mathrm{l}$ ) was higher among subjects with WC $\geq 94 \mathrm{~cm}(43 / 72$, $59.7 \%)$ with respect to those with WC $<94(20 / 49$, $40.8 \%)(P<0.05)$.

Fifty-six hypogonadic subjects ( 38 with $W C \geq 94 \mathrm{~cm}$ and 18 with WC $<94 \mathrm{~cm}$ ) were reevaluated after an 18-month period of testosterone replacement therapy (Table 3). In all subjects, as expected, there was a significant increase in total testosterone, $\mathrm{E}_{2}$, hematocrit, and hemoglobin and a decrease in LH and FSH. Prostate volume and PSA increased only in subjects with WC $\geq 94 \mathrm{~cm}(18.2 \pm 7.3 \mathrm{ml}$ at baseline vs $26.9 \pm 8.1 \mathrm{ml}$ after therapy; $0.55 \pm 0.21 \mu \mathrm{g} / \mathrm{l}$ at baseline vs $0.79 \pm 0.22 \mu \mathrm{g} / \mathrm{l} ; \quad P<0.0001)$. The two groups (WC $<94$ and $\geq 94 \mathrm{~cm}$ ) were similar for age $(28.5 \pm 10.1$ vs $30.7 \pm 9.2)$ and weighted CAG repeat length $(22.15 \pm 2.30$ vs $22.11 \pm 3.48)$.

Prostate volume, after testosterone replacement therapy, was significantly higher in subjects with WC $\geq 94 \mathrm{~cm}$ compared with controls $(26.9 \pm 8.1$ vs $21.0 \pm$ $5.4 \mathrm{ml} ; P<0.0001)$. Furthermore, prostate volume in KS untreated subjects, after 18 months of follow-up, showed a statistically significant increase only in subjects with WC $\geq 94 \mathrm{~cm}(18.0 \pm 5.2$ vs $22.0 \pm$ $5.0 \mathrm{ml} ; P<005 ; n=29)$ with respect to those with WC $<94 \mathrm{~cm}(15.1 \pm 4.4$ vs $15.8 \pm 5.1 \mathrm{ml} ; n=29)$. The increase in prostate volume in untreated vs treated KS subjects $(4.0 \pm 2.5$ vs $8.7 \pm 3.0 \mathrm{ml})$ was statistically significant $(P<0.001)$.

Thirty-four $(28.1 \%)$ KS subjects were affected by metabolic syndrome. Table 4 shows data of metabolic parameters in hypogonadic KS subjects' baseline and after testosterone replacement therapy.

\section{Discussion}

The aim of this study was to analyze a possible relationship between obesity and prostate volume in subjects affected by KS. Obesity, as measured by BMI, and more importantly visceral obesity, as measured by $\mathrm{WC}$, is the principal component of metabolic syndrome (18), and it is well known that patients with KS have higher risk of metabolic syndrome and insulin resistance. Bojesen et al., in a study of $71 \mathrm{KS}$ subjects, showed that almost half of the patients fulfilled the National Cholesterol Education Program (NCEP) Adult Treatment Panel III criteria for the metabolic syndrome. More precisely, in KS subjects, WC and plasma lipids were

Table 4 Hormonal and metabolic parameters and anthropometric measures in 56 hypogonadic KS subjects at baseline and after testosterone replacement therapy.

\begin{tabular}{lccc}
\hline & $\begin{array}{c}\text { Baseline } \\
(n=56)\end{array}$ & $\begin{array}{c}\text { After treat- } \\
\text { ment }(n=56)\end{array}$ & $\boldsymbol{P}$ \\
\hline Weight $(\mathrm{kg})$ & $87.6 \pm 11.5$ & $87.2 \pm 11.3$ & $\mathrm{NS}$ \\
$\mathrm{BMI}\left(\mathrm{kg} / \mathrm{m}^{2}\right)$ & $26.0 \pm 2.2$ & $25.7 \pm 4.2$ & $\mathrm{NS}$ \\
Waist $(\mathrm{cm})$ & $100.4 \pm 6.5$ & $100.1 \pm 8.2$ & $\mathrm{NS}$ \\
Total testosterone & $7.3 \pm 3.1$ & $15.2 \pm 4.9$ & $<0.00001$ \\
$\quad(\mathrm{nmol} / \mathrm{l})$ & & & \\
LH (IU/l) & $20.2 \pm 3.0$ & $16.3 \pm 4.8$ & $<0.0005$ \\
Glycemia (mg/dl) & $89.7 \pm 31.7$ & $87.0 \pm 21.2$ & $\mathrm{NS}$ \\
Insulin (mU/l) & $13.2 \pm 7.4$ & $11.3 \pm 8.0$ & $\mathrm{NS}$ \\
HOMA-IR & $2.8 \pm 1.7$ & $2.3 \pm 1.6$ & $<0.05$ \\
Total cholesterol & $233.2 \pm 68.4$ & $220.2 \pm 23.2$ & $\mathrm{NS}$ \\
$\quad(\mathrm{mg} / \mathrm{dl})$ & & & \\
HDL (mg/dl) & $46.8 \pm 11.1$ & $49.1 \pm 10.2$ & $\mathrm{NS}$ \\
Triglycerides (mg/dl) & $311.5 \pm 500.5$ & $145.4 \pm 79.7$ & $<0.05$ \\
\end{tabular}

NS, not statistically significant. 
significantly increased and HDL cholesterol was decreased. Furthermore, KS subjects had higher fasting plasma insulin levels and calculation of insulin sensitivity showed a significant decrease in insulin sensitivity (7). Such figures have been confirmed by Ishikawa et al., who found a prevalence of 34\% in 60 patients with KS. Again, KS subjects had increased LDL cholesterol and WC and decreased HDL compared with other men with azoospermia (8). The rationale for this study has been suggested by many studies describing an association between insulin resistance, hyperinsulinemia, elevated fasting glucose level, central obesity, and dyslipidemia, with higher risk of prostate diseases (13, 23).

We found a positive relationship between prostate volume and WC in Klinefelter subjects, confirming previous studies in other populations $(12,13)$. Furthermore, subjects with WC $\geq 94 \mathrm{~cm}$ had significantly higher prostate volume with respect to those with WC $<94 \mathrm{~cm}$. As expected, subjects with $\mathrm{WC} \geq 94 \mathrm{~cm}$ had significantly higher BMI, insulin plasma levels, HOMA index, total cholesterol, triglycerides, and glycemia with respect to those with $\mathrm{WC}<94 \mathrm{~cm}$, and they were more frequently hypogonadic. Interestingly, no relationship was found between prostate volume and hormonal levels and AR CAG length, and also dividing KS subjects on the basis of testosterone plasma levels $(<10.4$ or $\geq 10.4 \mathrm{nmol} / \mathrm{l}$ ), we found no statistical differences in prostate volume between the two considered groups. These findings support the hypothesis that obesity, insulin resistance, and glucose or lipid metabolism might be important for prostate size as well as androgens and/or estrogens (13, 22).

Other authors $(24,25,26)$, also in a population of young patients, have demonstrated that prostate volume was significantly associated with dyslipidemia (HDL and triglycerides). The authors have clearly indicated that prostate chronic inflammation has a primary role in triggering prostatic cells' overgrowth and that the exposure to dietary factors and metabolic variations represent potential causes for inflammation and immune dysregulation in the prostate (27). Then, we considered prostate growth in subjects treated with testosterone replacement therapy.

A recent meta-analysis shows that neither short-nor long-term androgen replacement therapy increases the risk of prostate growth (28). Interestingly, and supporting baseline data, in our study, we observed a statistically significant increase in prostate volume after treatment only in men with $W C \geq 94 \mathrm{~cm}$. In this group, prostate volume was even significantly higher with respect to prostate volume in controls. Interestingly, untreated men with WC $\geq 94 \mathrm{~cm}$ also had an increase in prostate volume after 18 months of followup, but the increase was significantly lower with respect to treated men with $W C \geq 94 \mathrm{~cm}$, suggesting that obesity per se is a risk factor for increase in prostate volume over time in KS patients and that testosterone treatment further amplifies this effect.

Several studies suggested that insulin resistance with secondary hyperinsulinemia is associated with prostatic enlargement (23). Hyperinsulinemia in fact is associated with an increased sympathetic nervous system activity and might contribute to increased smooth muscle tone of the prostate $(29,30)$. Furthermore, insulin has a structural similarity to insulin-like growth factor 1 and can bind its receptor, which might activate a complex pathway influencing prostate cell growth and proliferation.

Obesity seems to increase the risk for BPH. Dhale et al. (31) suggested that abdominal obesity and increasing serum insulin are associated with a higher risk of BPH. In a multicenter, cross-sectional, prospective study, it was reported that central obesity rather than overall obesity is a better predictor of lower urinary tract symptoms (30). Also disturbance in glucose and lipid metabolism, an integral part of insulin resistance syndrome, might be one of the important risk factors in the pathogenesis of $\mathrm{BPH}(13,32)$. Hyperglycemia might play a role by increasing cytosolic-free calcium in smooth muscle cells and neural tissue, leading to sympathetic nervous system activation, whereas the precise role and relative influence of hyperlipidemia in the pathogenesis of $\mathrm{BPH}$ is not clear. A recent study on an experimental rat model showed that, despite a reduction in circulating testosterone, obesity and insulin-resistance increased cell proliferation and resulted in diffuse epithelial hyperplasia in rat prostate $(33,34)$.

Previous studies have shown that the effect of testosterone substitution in hypogonadal men on the prostate gland is influenced by the (CAG) $n$ polymorphism of the AR gene $(17,35)$. Our data in KS do not confirm this result. Although further studies are necessary to clarify these aspects, it has to be noted that the effect of testosterone on prostate growth and the role of CAG repeat length in modulating the effects of testosterone in KS are still controversial $(17,19,36)$.

In conclusion, this study provides new insight into the relationship between WC and prostate volume, demonstrating that in $\mathrm{KS}$, visceral obesity is associated with prostate volume and influences prostate growth during testosterone replacement therapy. These latter findings might provide the basis for a better management and follow-up of KS subjects.

\section{Declaration of interest}

The authors declare that there is no conflict of interest that could be perceived as prejudicing the impartiality of the research reported.

\section{Funding}

This research did not receive any specific grant from any funding agency in the public, commercial or not-for-profit sector. 


\section{References}

1 Lanfranco F, Kamischke A, Zitzmann M \& Nieschlag E. Klinefelter's syndrome. Lancet $2004 \mathbf{3 6 4}$ 273-283. (doi:10.1016/S01406736(04)16678-6)

2 Klinefelter HF, Reifenstein EC \& Albright F. Syndrome characterized by gynecomastia, aspermatogenesis without a leydigism and increased excretion of follicle stimulating hormone. Journal of Clinical Endocrinology and Metabolism 19422 615-627. (doi:10. 1210/jcem-2-11-615)

3 Kübler A, Schulz G, Cordes U, Beyer J \& Krause U. The influence of testosterone substitution on bone mineral density in patients with Klinefelter's syndrome. Experimental and Clinical Endocrinology 1992100 129-132. (doi:10.1055/s-0029-1211192)

4 Campbell WA \& Price WH. Venous thromboembolic disease in Klinefelter's syndrome. Clinical Genetics 198119 275-280. (doi:10.1111/j.1399-0004.1981.tb00709.x)

5 Swerdlow AJ, Higgin CD, Schomaker MJ, Wright AF \& Jacobs PA. Mortality in patients with Klinefelter's syndrome in Britain: a cohort study. Journal of Clinical Endocrinology and Metabolism 2005 90 6516-6522. (doi:10.1210/jc.2005-1077)

6 Bojesen A \& Gravholt CH. Morbidity and mortality in Klinefelter syndrome (47XXY). Acta Paediatrica 2011100 807-813. (doi:10. 1111/j.1651-2227.2011.02274.x)

7 Bojesen A, Kristensen K, Birkebaek NH, Fedder J, Mosekilde L, Bennett P, Laurberg P, Frystyk J, Flyvbjerg A, Christiansen JS et al. The metabolic syndrome is frequent in Klinefelter's syndrome and is associate with abdominal obesity and hypogonadism. Diabetes Care 200629 1591-1598. (doi:10.2337/dc06-0145)

8 Ishikawa T, Yamaguchi K, Kondo Y, Takenaka A \& Fujisawa M. Metabolic syndrome in men with Klinefelter's syndrome. Urology 200871 1109-1113. (doi:10.1016/j.urology.2008.01.051)

9 Parsons JK, Sarma AV, McVary K \& Wei JT. Obesity and benign prostatic hyperplasia: clinical connections, emerging etiological paradigms and future directions. Journal of Urology $2013 \mathbf{1 8 9}$ S102-S106. (doi:10.1016/j.juro.2012.11.029)

10 Giovannucci E, Rimm EB, Chute CG, Kawachi I, Colditz GA, Stampfer MJ \& Willett WC. Obesity and benign prostatic hyperplasia. American Journal of Epidemiology 1994140 989-1002.

11 Kristal AR, Arnold KB, Schenk JM, Neuhouser ML, Weiss N, Goodman P, Antvelink CM, Penson DF \& Thompson IM. Race/ethnicity, obesity, health related behaviors and the risk of symptomatic benign prostatic hyperplasia: results from the prostate cancer prevention trial. Journal of Urology $2007 \mathbf{1 7 7}$ 1395-1400. (doi:10.1016/j.juro.2006.11.065)

12 Alokail MS, Al-Daghri NM, Al-Attas OS, Alkharfy KM, Sabico SB \& Ullrich A. Visceral obesity and inflammation markers in relation to serum prostate volume biomarkers among apparently healthy men. European Journal of Clinical Investigation 2011 41 987-994. (doi:10.1111/j.1365-2362.2011.02496.x)

13 Vikram A, Jena G \& Ramarao P. Insulin-resistance and benign prostatic hyperplasia: the connection. European Journal of Pharmacology $2010 \mathbf{6 4 1}$ 75-81. (doi:10.1016/j.ejphar.2010. 05.042 )

14 Marks LS, Mazer NA, Mostaghel E, Hess DL, Dorey FJ, Epstein JI, Veltri RW, Makarov DV, Partin AW, Bostwick DG et al. Effect of testosterone replacement therapy on prostate tissue in men with late-onset hypogonadism: a randomized controlled trial. Journal of the American Medical Association $20062962351-2361$. (doi:10.1001/jama.296.19.2351)

15 Meikle AW, Arver S, Dobs AS, Adolfsson J, Sanders SW, Middleton RG, Stephenson RA, Hoover DR, Rajaram L \& Mazer NA. Prostate size in hypogonadal men treated with a nonscrotal permeation-enhanced testosterone transdermal system. Urology $1997 \mathbf{4 9}$ 191-196. (doi:10.1016/S00904295(96)00445-1)

16 Rhoden EL \& Morgentaler A. Risks of testosterone-replacement therapy and recommendations for monitoring. New England Journal of Medicine $2004 \quad \mathbf{3 5 0}$ 482-492. (doi:10.1056/ NEJMra022251)
17 Zitzmann M, Depenbusch M, Gromoll J \& Nieschlag E. $\mathrm{X}$-chromosome inactivation patterns and androgen receptor functionality influence phenotype and social characteristics as well as pharmacogenetics of testosterone therapy in Klinefelter patients. Journal of Clinical Endocrinology and Metabolism 200489 6208-6217. (doi:10.1210/jc.2004-1424)

18 Alberti KG, Zimmet P \& Shaw J. Metabolic syndrome - a new world-wide definition. A consensus statement from the International Diabetes Federation. Diabetic Medicine 200623 469-480. (doi:10.1111/j.1464-5491.2006.01858.x)

19 Ferlin A, Schipilliti M, Vinanzi C, Garolla A, Di Mambro A, Selice R, Lenzi A \& Foresta C. Bone mass in subjects with Klinefelter syndrome: role of testosterone levels and androgen receptor gene CAG polymorphism. Journal of Clinical Endocrinology and Metabolism 2011960 739-745. (doi:10.1210/jc.20101878)

20 Kubota T, Nonoyama S, Tonoki H, Masuno M, Imaizumi K, Kojima M, Wakui K, Shimadzu M \& Fukushima Y. A new assay for the analysis of X-chromosome inactivation based on methylationspecific PCR. Human Genetics 19991041 49-55. (doi:10.1007/ s004390050909)

21 Bhasin S, Cunningham GR, Hayes FJ, Matsumoto AM, Snyder PJ, Swerdloff RS \& Montori VM. Testosterone therapy in adult men with androgen deficiency syndromes: an Endocrine Society clinical practice guideline. Journal of Clinical Endocrinology and Metabolism 2006 91 1995-2010. (doi:10.1210/jc.2005-2847)

22 Kälkner KM, Kubicek G, Nilsson J, Lundell M, Levitt S \& Nilsson S. Prostate volume determination: differential volume measurements comparing CT and TRUS. Radiotherapy and Oncology 200681 179-183. (doi:10.1016/j.radonc.2006.10.003)

23 De Nunzio C, Kramer G, Marberger M, Montironi R, Nelson W, Schröder F, Sciarra A \& Tubaro A. The controversial relationship between benign prostatic hyperplasia and prostate cancer: the role of inflammation. European Urology 201160 106-117. (doi:10.1016/j.eururo.2011.03.055)

24 Gacci M, Vignozzi L, Sebastianelli A, Salvi M, Giannessi C, De Nunzio C, Tubaro A, Corona G, Rastrelli G, Santi R et al. Metabolic syndrome and lower urinary tract symptoms: the role of inflammation. Prostate Cancer and Prostatic Diseases 201316 101-106. (doi:10.1038/pcan.2012.44)

25 Vignozzi L, Gacci M, Cellai I, Santi R, Corona G, Morelli A, Rastrelli G, Comeglio P, Sebastanelli A, Maneschi E et al. Fat boosts, while androgen receptor activation counteracts, BPHassociated prostate inflammation. Prostate 2013 73 789-800. (doi:10.1002/pros.22623)

26 Lotti F, Corona G, Colpi GM, Filimberti E, Degli Innocenti S, Mancini M, Baldi E, Noci I, Forti G, Adorini L et al. Elevated body mass index correlates with higher seminal plasma interleukin 8 levels and ultrasonographic abnormalities of the prostate in men attending an andrology clinic for infertility. Journal of Endocrinological Investigation 201134 336-342. (doi:10.3275/7855)

27 Fibbi B, Penna G, Morelli A, Adorini L \& Maggi M. Chronic inflammation in the pathogenesis of benign prostatic hyperplasia. International Journal of Andrology 2010 33 475-488. (doi:10. 1111/j.1365-2605.2009.00972.x)

28 Cui Y \& Zhang Y. The effect of androgen-replacement therapy on prostate growth: a systematic review and meta-analysis. European Urology 2013. In press. (doi:10.1016/j.eururo.2013.03.042)

29 Rohrmann S, Smit E, Giovannucci E \& Platz EA. Association between markers of the metabolic syndrome and lower urinary tract symptoms in the Third National Health and Nutrition Examination Survey (NHANES III). International Journal of Obesity 200529 310-316. (doi:10.1038/sj.ijo.0802881)

30 Parsons JK, Carter HB, Partin AW, Windham BG, Metter EJ, Ferrucci L, Landis P \& Platz EA. Metabolic factors associated with benign prostatic hyperplasia. Journal of Clinical Endocrinology and Metabolism 200691 2562-2568. (doi:10.1210/jc.2005-2799)

31 Dahle SE, Chokkalingam AP, Gao YT, Deng J, Stanczyk FZ \& Hsing AW. Body size and serum levels of insulin and leptin in 
relation to the risk of benign prostatic hyperplasia. Journal of Urology 2002168 599-604. (doi:10.1016/S0022-5347(05) 64687-3)

32 Sarma AV, Parsons JK, McVary K \& Wei JT. Diabetes and benign prostatic hyperplasia/lower urinary tract symptoms - what do we know? Journal of Urology 2009182 32-37. (doi:10.1016/j.juro. 2009.07.088)

33 Ribeiro DL, Pinto ME, Rafacho A, Bosqueiro JR, Maeda SY, Anselmo-Franci JA, Taboga SR \& Góes RM. High-fat diet obesity associated with insulin resistance increases cell proliferation, estrogen receptor, and PI3K proteins in rat ventral prostate. Journal of Andrology 201233 854-865. (doi:10.2164/jandrol. 111.016089)

34 Damas-Souza DM, Oliveira CA \& Carvalho HF. Insulin affects tissue organization and the kinetics of epithelial cell death in the rat ventral prostate after castration. Journal of Andrology 201031 631-634. (doi:10.2164/jandrol.110.010306)
35 Zitzmann M, Depenbusch M, Gromoll J \& Nieschlag E. Prostate volume and growth in testosterone-substituted hypogonadal men are dependent on the CAG repeat polymorphism of the androgen receptor gene: a longitudinal pharmacogenetic study. Journal of Clinical Endocrinology and Metabolism 200388 2049-2054. (doi:10.1210/jc.2002-021947)

36 Foresta C, Caretta N, Palego P, Ferlin A, Zuccarello D, Lenzi A \& Selice R. Reduced artery diameters in Klinefelter syndrome. International Journal of Andrology 201235 720-725. (doi:10. $1111 / \mathrm{j} .1365-2605.2012 .01269 . x)$

Received 11 June 2013

Revised version received 27 August 2013

Accepted 3 September 2013 